\title{
Deformation of Steel Slag Asphalt Mixtures Under Normal Temperature Water Immersion
}

\author{
Chao Wang ${ }^{1,2}$ and Caili Zhang ${ }^{2 *}$ \\ ${ }^{1}$ Jiangsu JITRI Road Engineering Technology and Equipment Research Institute Co., Ltd., XuZhou, China, ${ }^{2}$ School of Civil \\ Engineering and Transportation, Hebei University of Technology, Tianjin, China
}

OPEN ACCESS

Edited by:

Yunchao Tang,

Guangxi University, China

Reviewed by:

Zhenliang Jiang,

Ryerson University, Canada

Shengjie Jiao,

Chang'an University, China

Wanhui Feng,

Zhongkai University of Agriculture and

Engineering, China

*Correspondence:

Caili Zhang

17695799230@163.com

Specialty section:

This article was submitted to

Environmental Degradation of

Materials,

a section of the journal

Frontiers in Materials

Received: 01 June 2021

Accepted: 05 July 2021

Published: 16 August 2021

Citation:

Wang C and Zhang C (2021)

Deformation of Steel Slag Asphalt

Mixtures Under Normal Temperature

Water Immersion.

Front. Mater. 8:718516.

doi: 10.3389/fmats.2021.718516
To study the deformation resistance of steel slag asphalt mixtures (SSAMs) under rainy conditions, limestone-asphalt mixtures (LAMs) and SSAM were soaked in water at room temperature for 120 days and rutting tests and triaxial compression tests were carried out. The results show that the deformation resistance of SSAM was improved after 120 days of immersion, the cohesion did not decrease significantly, and the internal friction angle increased by $25.1 \%$; the deformation resistance of LAM decreased significantly, the cohesion decreased by $27.1 \%$, and the internal friction angle decreased by $21.1 \%$. To better understand the reason for the increased anti-deformation ability, adhesion tests of asphalt and microscopic studies of the steel slag surface were performed. The experimental results showed that the cohesion of steel slag did not decrease significantly after immersion because of the excellent adhesion between steel slag and asphalt. The increased internal friction angle was caused by calcium hydroxide and other crystals formed on the surface of the steel slag mixture after immersion, which increased the surface roughness of the steel slag aggregates and the internal friction angle of the SSAM. The mechanical properties of semirigid asphalt pavement were analyzed by ANSYS. It was determined that the shear stress of this type of pavement is large, and it can easily produce permanent deformations. Under the influence of moisture, the anti-deformation ability of SSAMs can grow, which promotes the high-temperature deformation resistance of asphalt pavement. Based on a test road used for 2 years, the SSAM pavement exhibited no pavement problems, such as cracking, loosening, or rutting, which indicates good practical road performance.

Keywords: steel slag asphalt mixture, deformation resistance, cohesion, internal friction angle, crystalline matters

\section{INTRODUCTION}

China is the largest steel-producing country, accounting for about $50 \%$ of global steel production. By the end of 2020, China's steel production reached 1.05 billion tons, with an annual growth of $5.4 \%$. Steel slag is the waste generated during steel making in the steel refining process, which corresponds to approximately $10-15 \%$ of crude steel output.

Steel slag is a reusable resource in many fields, and it can be employed as a soil conditioner or a steel slag cement compound (Lian et al., 2021). However, in order to be used in such applications, steel slag must go through a complex processing treatment. This process requires significant manpower and material resources and has a low utilization rate. Therefore, to date, the comprehensive utilization rate of steel slag in China is only about $38.7 \%$. 
Considering conventional methods of industrial and construction waste utilization, most solid waste is used as concrete aggregate (Tang et al., 2020; Tang et al., 2021a; Tang et al., 2021b). If a significant amount of steel slag can be applied in road-engineering projects, this would not only solve the urgent challenges regarding material shortages but would also help to reduce steel slag pollution on land. Therefore, numerous researchers around the world have evaluated whether steel slag can be used in asphalt mixtures.

The chemical composition of steel slag has an important influence on its applicability. The iron content in steel slag impacts its heating efficiency, such that a high iron content corresponds to a high heating efficiency (Wan et al., 2018). Additionally, as the steel slag content in asphalt mixtures increases, the thermal conductivity of the asphalt mixture first increases and then decreases (Barišić et al., 2017). Alkaline substances in steel slag can increase the concentration of asphalt components on the aggregate surface and enhance the adhesion between asphalt and steel slag (Jiao et al., 2020). Some heavy metals may also exist in steel slag. Reports have shown that the application of steel slag in highways does not lead to environmental pollution (Liu et al., 2020).

Steel slag asphalt mixtures (SSAMs) have many unique characteristics. If the free calcium oxide content in steel slag is too high, expansion cracking may occur during use, which could lead to performance degradation of the mixture. However, the influence of steel slag expansion on asphalt pavement can be reduced by properly designing the surface water isolation structure (Ma et al., 2020). If steel slag aggregates are used in an asphalt mixture, its permanent deformation resistance will be improved (Ameri et al., 2013). This means that replacing the skeleton of coarse aggregates with steel slag aggregates could improve the rutting resistance of the mixture (Ameli et al., 2020). Furthermore, it has been demonstrated that it is technically feasible to use steel slag as the coarse aggregate (Chen and Wei, 2016).

In addition to enhancing the deformation resistance of SSAM, steel slag aggregates can improve the anti-fatigue cracking performance of asphalt mixtures (Qazizadeh et al., 2018; Ziaee and Behnia, 2020), as well as their low-temperature performance (Chai et al., 2020). The improvement mechanism is governed by the alkalinity and a large specific surface area of steel slag (Zhu et al., 2020) and benefits from the physical anchoring and chemical adhesion effects between steel slag and asphalt (Pathak et al., 2020).

In an open-graded friction course, replacing part of the coarse aggregate with steel slag can improve the water damage resistance of the material. Incorporating 75\% steel slag aggregate into OGFC promoted good road performance (Pattanaik et al., 2021). It was also demonstrated that using steel slag as coarse aggregate improved the friction resistance of OGFC; specifically, it was suggested that in hilly and rainy areas, $50 \%$ steel slag should be used instead of coarse aggregate in OGFC mixtures to improve the water damage resistance of roads (Preti et al., 2019).

In snow melting pavement, steel slag can improve the microwave heating efficiency to enhance snow melting on the road. Asphalt concrete mixed with $60 \%$ steel slag can effectively improve the snow melting efficiency of thermally conductive asphalt concrete and pavement temperature distribution (Lyu et al., 2021). When steel slag is used as the microwave deicing aggregate in an asphalt mixture, the steel slag serves as a microwave absorption reinforcement material to improve the heating efficiency of the asphalt mixture (Gao et al., 2017). Previously, a co-precipitation method was used to modify the steel slag particles, which increased the $\mathrm{Fe}_{3} \mathrm{O}_{4}$ content on the surface to completely replace the fine aggregate; after microwave heating, the internal temperature of the modified SSAM was $74.4 \%$ higher than that of the basalt asphalt mixture (Gulisano et al., 2020). Overall, adding steel slag and using microwave heating can clearly improve the performance of emulsified asphalt repair materials (Liu et al., 2017).

The application of steel slag in the gravel seal can recover industrial waste, reduce the consumption of natural resources, and promote the development of economic pavement maintenance technology by reducing $\mathrm{CO}_{2}$ emissions (Bonoli et al., 2020). In a warm mixture, adding steel slag can improve the water damage resistance of the asphalt mixture (Wei et al., 2020).

\section{Objective}

Although research regarding steel slag in general has been fruitful, the enhancement of SSAM's anti-deformation ability is still not entirely understood. Steel slag is a material that is easily affected by water. Therefore, in the rainy season, changes in the antideformation performance of SSAMs must be considered to evaluate the potential applicability of steel slag aggregates in road engineering.

The main purpose of the present work was to study the causes and magnitudes of the changes to SSAMs' anti-deformation performance under normal temperature immersion. The water stability, low-temperature deformation performance, and fatigue performance of SSAMs were also studied following normal temperature immersion.

\section{Research Approach}

In this study, SSAM was used as the research object, and a limestone-asphalt mixture was used as a reference. Rutting tests, triaxial compression tests, adhesion tests, and atomic force scanning tests were conducted to study the macroscopic and microscopic changes in the anti-deformation properties of asphalt mixtures immersed in water at $30^{\circ} \mathrm{C}$ for 120 days during the summer. A water stability test, a low-temperature bending test, and a fatigue test were also employed to detect the changes in the performance of SSAMs after immersion.

\section{MATERIALS AND METHODS}

\section{Raw Materials and Specimens}

For the asphalt base of penetration $(70 \pm 0.01 \mathrm{~mm})$, steel slag aggregates and limestone aggregates from Tangshan, Hebei, were selected as the raw materials. After testing, the raw materials met the relevant requirements of Chinese standard JTG F40-2004. The parameters of these aggregate-related materials are shown in Table 1. 
TABLE 1 | Measured parameters of steel slag and limestone aggregates.

\begin{tabular}{|c|c|c|c|c|c|}
\hline Aggregate type & $\begin{array}{c}\text { Particle size } \\
\text { specification }(\mathrm{mm})\end{array}$ & $\begin{array}{c}\text { Apparent density } \\
\left(\mathbf{g} \cdot \mathrm{cm}^{-3}\right)\end{array}$ & $\begin{array}{c}\text { Water absorption } \\
(\%)\end{array}$ & $\begin{array}{c}\text { Crushing value } \\
(\%)\end{array}$ & $\begin{array}{c}\text { Los Angeles } \\
\text { abrasion value } \\
(\%)\end{array}$ \\
\hline \multirow[t]{3}{*}{ Steel slag } & $10-15$ & 3.416 & 2.3 & 9.0 & 11.0 \\
\hline & $5-10$ & 3.455 & 2.7 & - & - \\
\hline & $0-5$ & 3.495 & 3.0 & - & - \\
\hline \multirow[t]{3}{*}{ Limestone } & $10-15$ & 2.725 & 0.4 & 13.8 & 24.5 \\
\hline & $5-10$ & 2.736 & 0.5 & - & - \\
\hline & $0-5$ & 2.748 & 0.6 & - & - \\
\hline
\end{tabular}

TABLE 2 | Marshall indices of asphalt mixtures.

\begin{tabular}{|c|c|c|c|c|c|}
\hline $\begin{array}{l}\text { Type of } \\
\text { mixture }\end{array}$ & $\begin{array}{l}\text { Oil stone } \\
\text { ratio (\%) }\end{array}$ & $\begin{array}{c}\text { Void fraction } \\
(\%)\end{array}$ & Stability (kN) & $\begin{array}{c}\text { Flow value } \\
(0.1 \mathrm{~mm})\end{array}$ & $\begin{array}{c}\text { Bulk specific } \\
\text { gravity }\left(\mathrm{g} \cdot \mathrm{cm}^{-3}\right)\end{array}$ \\
\hline SSAM & 5.1 & 4.0 & 11.3 & 28 & 2.753 \\
\hline LAM & 4.7 & 4.3 & 10.0 & 33 & 2.498 \\
\hline
\end{tabular}

TABLE 3 | Preliminary gradation quality.

\begin{tabular}{|c|c|c|c|c|c|c|c|c|c|c|}
\hline $\begin{array}{l}\text { Mesh } \\
\text { size } \\
(\mathrm{mm})\end{array}$ & 16 & 13.2 & 9.5 & 4.75 & 2.36 & 1.18 & 0.6 & 0.3 & 0.15 & 0.075 \\
\hline Passing mass (\%) & 100.0 & 95.0 & 68.9 & 46.2 & 30.0 & 20.3 & 14.2 & 9.9 & 7.0 & 5.0 \\
\hline
\end{tabular}

Steel slag was used for the coarse aggregate and fine aggregate of the AC-13 SSAM, and limestone powder was used as a filler. Limestone was used for the coarse aggregate, fine aggregate, and mineral powder of the AC-13 limestone-asphalt mixture (LAM). The relevant Marshall volume parameters are shown in Table 2, and the unified mixture gradation is presented in Table 3.

According to the Marshall test's results, and to ensure consistent height and uniformity of the test specimens, a press machine and rut-forming machine were used to separately generate specimens' triaxial compression and rutting tests. The size of the static pressure specimen was $250 \mathrm{~mm}$ in diameter and $160 \mathrm{~mm}$ in height, and these specimens were further processed into samples $150 \mathrm{~mm}$ in diameter and $150 \mathrm{~mm}$ in height; the size of each rutting specimen was $300 \mathrm{~mm} \times 300 \mathrm{~mm} \times 50 \mathrm{~mm}$.

The micro test samples required special treatments because atomic force microscopy (AFM) generally adopts a tapping mode. The sample size is typically less than $1 \mathrm{~cm}^{2}$, the height should be controlled below $0.5 \mathrm{~cm}$, and the surface fluctuation of the sample should not exceed $15 \mu \mathrm{m}$, otherwise the needle tip may be damaged. It was, therefore, necessary to cut the Marshall specimen into 3-5 $\mathrm{mm}$ slices, dissolve them in trichloroethylene, select the slices that met the test requirements, and wrap them with a layer of asphalt film.

The prepared triaxial compression specimens, rutting specimens, Marshall specimens, trabecular specimens, and microscopic specimens were immersed in normal temperature water in the summer for 120 days.
TABLE 4 | Fatigue test parameters.

Test parameters

Value

Prestress $(M)$

Loading frequency $(\mathrm{Hz})$

Loading waveform

Test temperature $\left({ }^{\circ} \mathrm{C}\right)$

Stress ratio

The stress ratio is the ratio of the test pressure to the maximum pressure that the specimen could bear.

\section{Testing Methods}

\section{Water Stability Test Method}

Water resistance tests, rutting tests, and low-temperature bending tests were conducted on the asphalt mixtures in strict accordance with the technical requirements of Chinese standard JTG E20-2011.

\section{Fatigue Tests}

The fatigue testing machine used in this study was a universal testing machine (UTM), a multifunctional testing machine. The equipment was mainly composed of a refrigeration system, a hydraulic system, a temperature system, a pressure system, splitting accessories, a transverse displacement sensor, and a spindle displacement sensor. The instrument continuously applied pressure to the splitting accessories through the spindle, and the splitting accessories applied force to the Marshall specimen. The transverse displacement sensor was used to measure the transverse deformation of each Marshall specimen under pressure. 


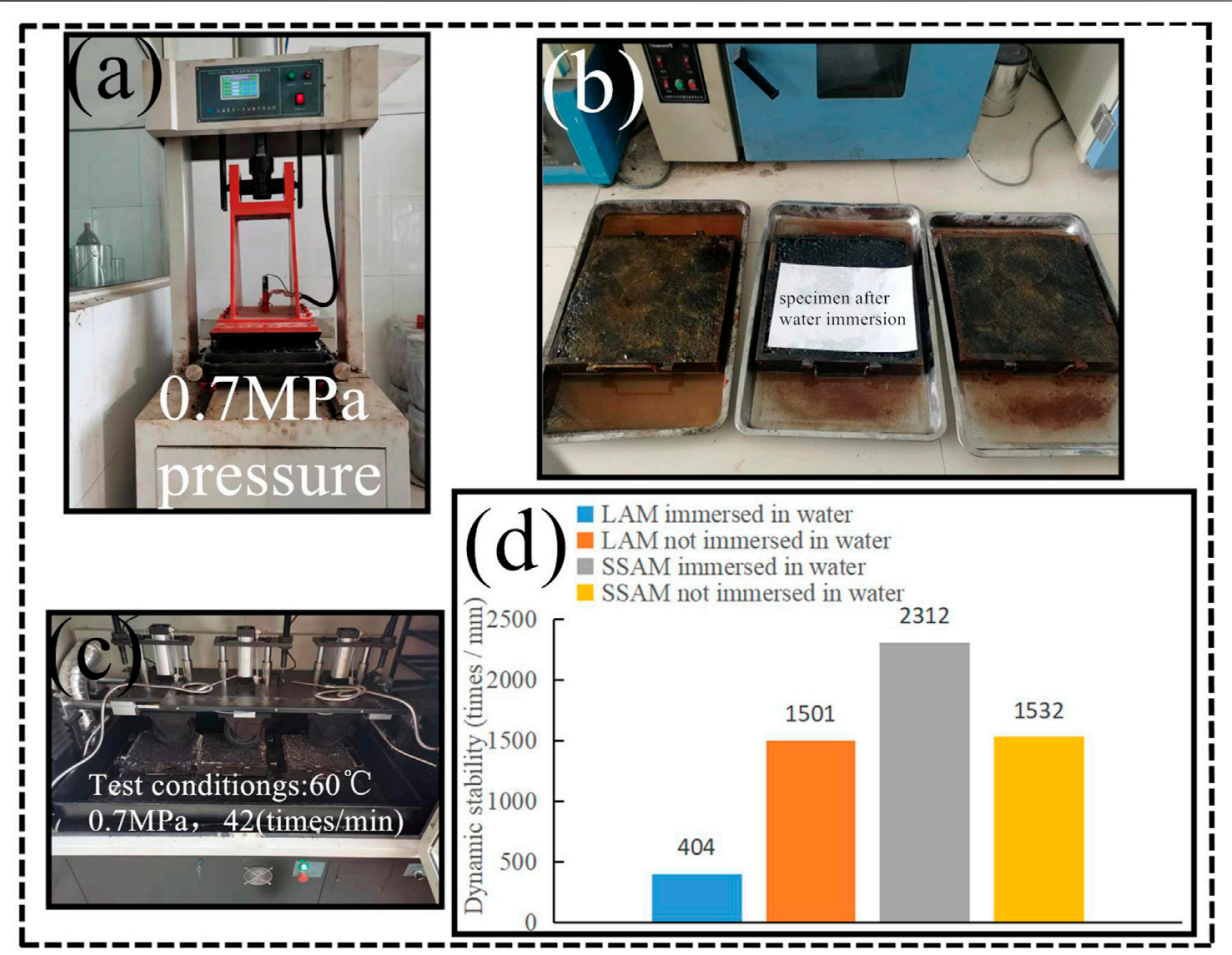

FIGURE 1 | Rutting performance of asphalt mixtures: (A) test piece formation; (B) test piece soaking; (C) rutting test; and (D) results.

During these tests, the displacement sensor accessories were first installed on the Marshall specimen. Then the specimens were maintained at $15^{\circ} \mathrm{C}$ for at least $6 \mathrm{~h}$. At that time, the test was begun immediately, according to the parameters compiled in Table 4.

\section{Triaxial Tests}

The equipment used for the triaxial tests was a UTM-30 multifunctional testing machine, and the test temperature was $60^{\circ} \mathrm{C}$. The instrument was mainly composed of a pressure chamber, an axial pressure system, a confining pressure application system, data acquisition system, and a control system.

The standard size of each specimen for the triaxial test was $100 \mathrm{~mm}$ in diameter and $150 \mathrm{~mm}$ in height. During the test, the control and acquisition systems of the triaxial apparatus were turned on, the designated confining pressure was applied, and the axial load was applied according to the constant loading rate. For specimens with a height of $150 \mathrm{~mm}$, the constant loading rate was $7.5 \mathrm{~mm} / \mathrm{min}$, which corresponds to an axial strain rate of about $0.05 \mathrm{~mm} /(\mathrm{mmmin})$. When the peak value of axial pressure was reached, the test was stopped. If there was no peak value, the test was stopped when the strain reached $20 \%$. After each test, the computer automatically calculated the cohesion and internal friction angle.

\section{RESULTS AND DISCUSSION}

\section{Analysis of Rutting Test Results}

Numerous studies have demonstrated that the deformation of asphalt pavement under a certain load undergoes the following three stages: 1) a further compaction stage, wherein the asphalt mixture is further compacted before about 1,000 load cycles; 2) the creep stability stage, wherein the asphalt mixture has been fully compacted (this deformation stage mainly involves slow creep under the load cycle); and 3) spalling in the accelerated deformation stage, wherein part of the asphalt spalling generates strain, and the strain rate of the asphalt mixture increases rapidly with time because of the influence of moisture. Therefore, moisture must be considered when evaluating the asphalt mixtures' permanent deformation resistance to understand its performance during the rainy season.

In China, the evaluation index of the rutting test is dynamic stability, which refers to the walking times of a standard axle load borne by the asphalt mixture when a deformation of $1 \mathrm{~mm}$ occurs at $60^{\circ} \mathrm{C}$; the larger the value, the better the anti-rutting performance of the asphalt mixture. The process of forming the test pieces is shown in Figure 1A, the soaking of the specimen is shown in Figure 1B, the rutting test is shown in Figure 1C, and the test results are shown in Figure 1D.

As shown in the figure, the dynamic stability of LAM after immersion decreased by $73 \%$ relative to the sample that was not immersed. In contrast, the dynamic stability of SSAM after immersion increased by $50 \%$ relative to that without immersion. These results indicated that the deformation resistance of LAM decreased after immersion, whereas SSAM endured some changes that increased the deformation resistance of SSAM upon immersion in water. The changes in deformation resistance are closely related to the cohesion and internal friction of the asphalt mixtures. Therefore, to further explore 


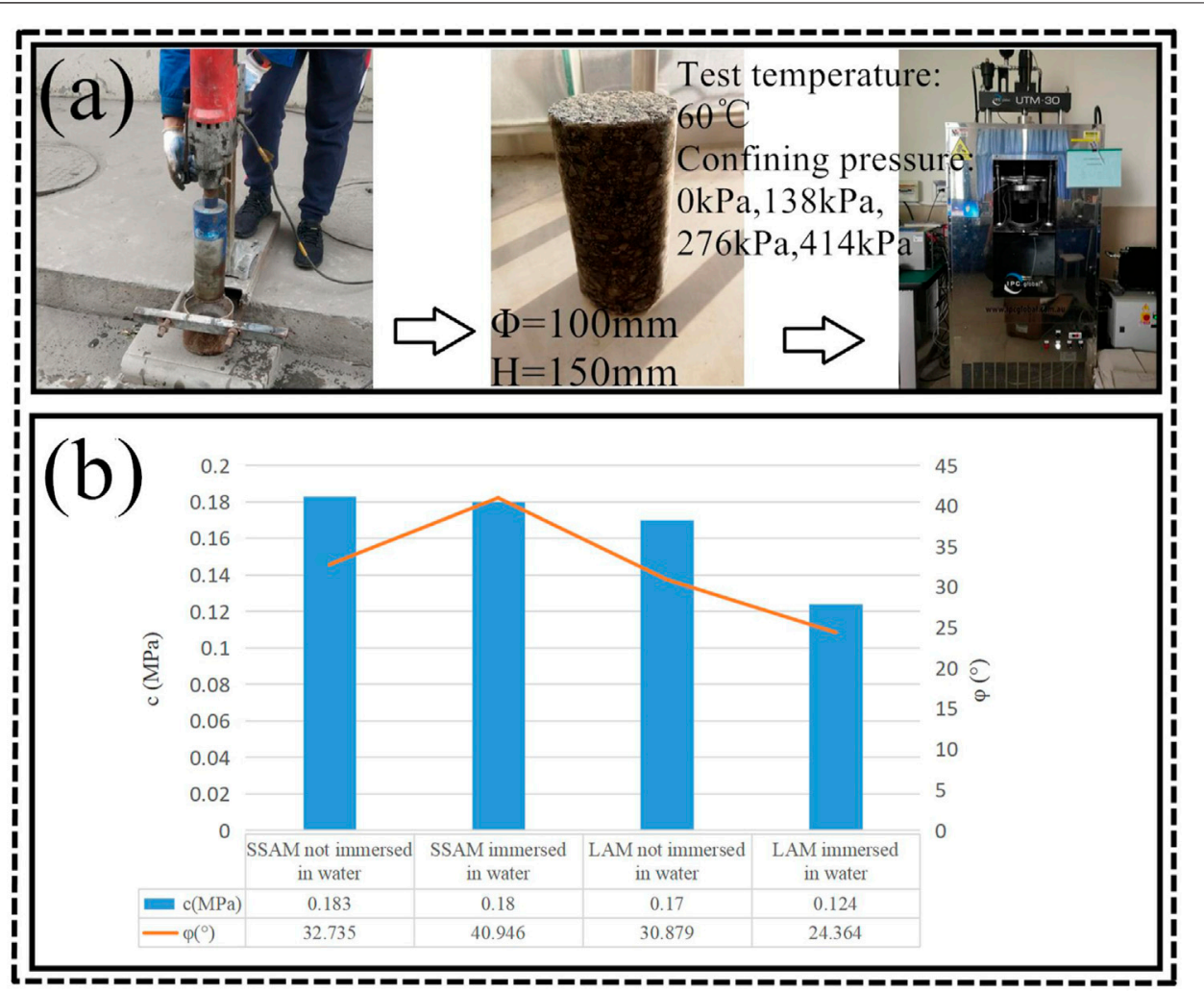

FIGURE 2 | Triaxial tests: (A) testing process and (B) results.

the origin of this phenomenon, triaxial compression tests were performed.

\section{Triaxial Compression Tests}

Asphalt mixtures are viscoelastic materials, meaning that under the action of shear stress, viscoelastic deformation of asphalt mixture occurs. The main properties that contribute to the shear capacity of an asphalt mixture are cohesion (c) and the internal friction angle $(\varphi)$. To study the cohesion and internal friction angles of LAM and SSAM before and after immersion, triaxial compression tests were performed. The test procedures are shown in Figure $\mathbf{2 A}$, and the test results are shown in Figure 2B.

The results of the triaxial compression tests indicate that the cohesion of SSAM does not decrease significantly, but that of LAM decreases by $27.1 \%$; the internal friction angle of SSAM increases by $25.1 \%$ and that of LAM decreases by $21.1 \%$. The reduction in LAM cohesion and the internal friction angle are the main reasons for this material's decreased deformation resistance after immersion, while the increase in the SSAM internal friction angle and the stability of its cohesion are the main reasons for the improvement of deformation resistance in the case of SSAM. To further explore the reasons why the cohesion of the SSAM remained unchanged and the internal friction increased after immersion, it was necessary to carry out asphalt adhesion and micro tests.

\section{Asphalt Adhesion Tests}

The adhesion test of asphalt is typically used to evaluate the adhesion between the aggregate surface and the asphalt to understand the anti-stripping ability of the asphalt film on the aggregate surface. According to the anti-stripping ability, the adhesion can be divided into five grades, where grade 5 is the best and grade 1 is the worst. The sample should be boiled for $3 \mathrm{~min}$ in a conventional laboratory, but to further study the aggregate adhesion, the boiling time in this study was extended to $6 \mathrm{~min}$; the test results are shown in Figure 3C.

As the boiling time increased, the adhesion grade of the steel slag and asphalt changed from 5 to 4 , while that of limestone changed from 4 to 2 . Figures 3A,B present test photos showing the asphalt adhesion of limestone and steel slag at $6 \mathrm{~min}$. It is clear that the adhesion of steel slag/asphalt is much better than that of limestone/asphalt. This result indicates that the interface between steel slag and asphalt has a stronger resistance to high temperature and water immersion than the limestone-asphalt interface. This indirectly explains why the cohesion of SSAMs is only slightly reduced after long-term water immersion.

In the asphalt mixtures, the main function of asphalt is to provide the required cohesion and stabilizing force. When asphalt is gradually stripped from the asphalt mixture, the cohesion and stability also decrease, which consequently reduces the deformation resistance of the asphalt mixture. 


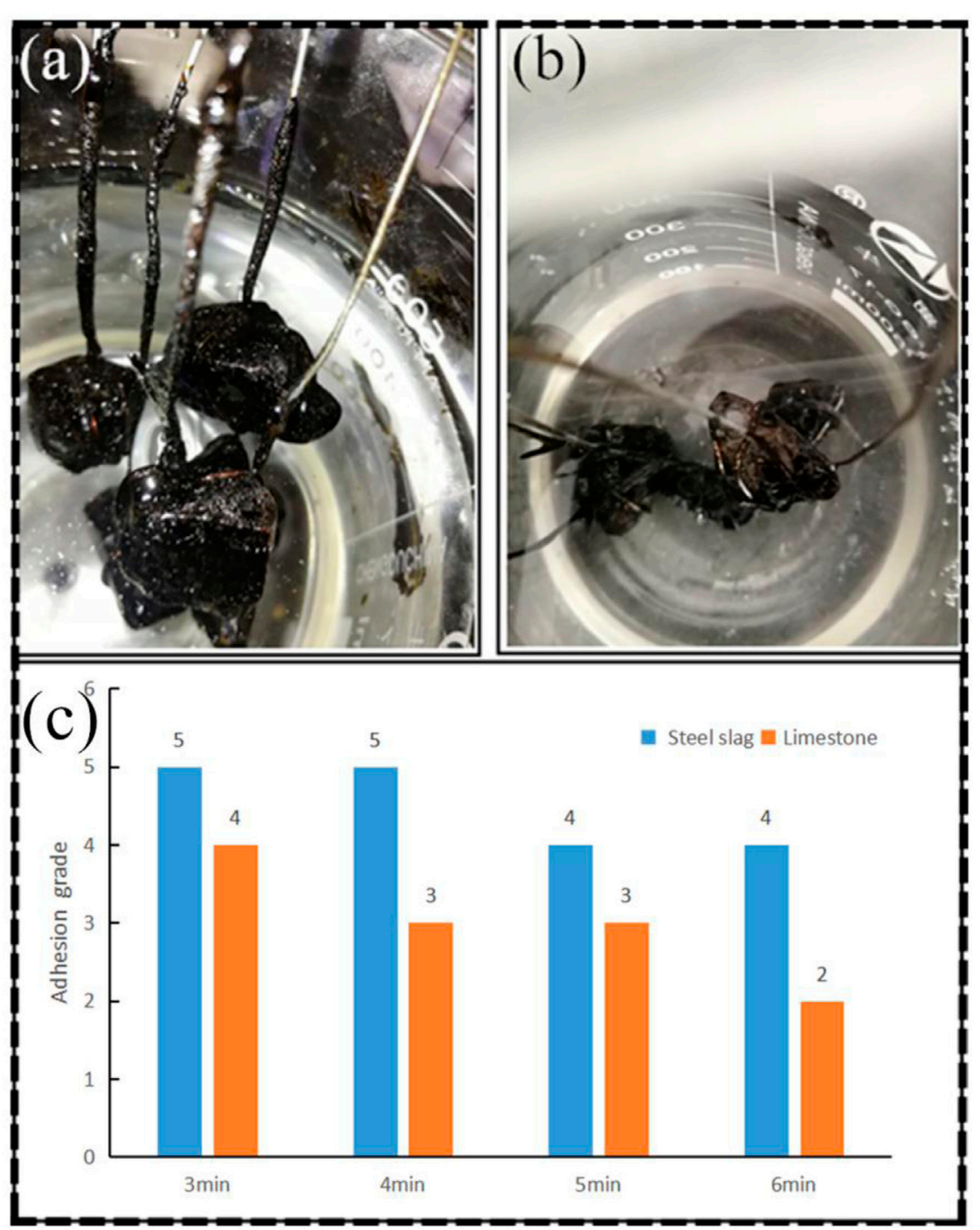

FIGURE 3 | Adhesion tests between aggregates and asphalt: (A) steel slag aggregate adhesion test at 6 min; (B) limestone aggregate adhesion test at 6 min; and (C) results of aggregate adhesion.

\section{Microscopic Tests}

The longitudinal resolution of AFM images is less than $0.01 \mathrm{~nm}$, which allows us to distinguish atomic level surface changes and to calculate the roughness of samples. Therefore, AFM was used to study the surface changes of steel slag before and after immersion.

The asphalt steel slag slices were soaked in trichloroethylene after immersion, and the asphalt on the surface was removed. Then, AFM scans were carried out on the steel slag slices. The testing process is shown in Figure 4A.

Figure 4B shows the electron microscope scanning diagram of a specimen after 60 days of immersion, revealing hexagonal platelike crystals. Figure 4C presents the atomic force scanning diagram of the sample immersed for 120 days, which clearly shows crystals that make the steel slag surface uneven.

Using Gwyddion software for data visualization and analysis, the surface area data from atomic force scanning was obtained, as shown in Figures 4D,E.
According to Figures 4D,E, the ratios of the steel slag surface area to the scanning area were 1.29 and 1.93 before and after soaking, respectively. This means that over the same scanning area, the surface area of steel slag soaked in room temperature water for 120 days was 1.5 times of that of non-immersed steel slag aggregate.

The aforementioned phenomenon indicates that with the prolongation of the soaking time, water soaked the steel slag along cracks and initiated hydration reactions on the surface of steel slag. This increased the surface roughness of the steel slag aggregate and the internal friction angle of the SSAM. Higher internal friction can enhance the anti-deformation ability of an asphalt mixture, which also improves its anti-rutting performance.

\section{Other Road Performance Tests}

The water stability, low-temperature deformation performance, and fatigue performance of LAM and SSAM after immersion 


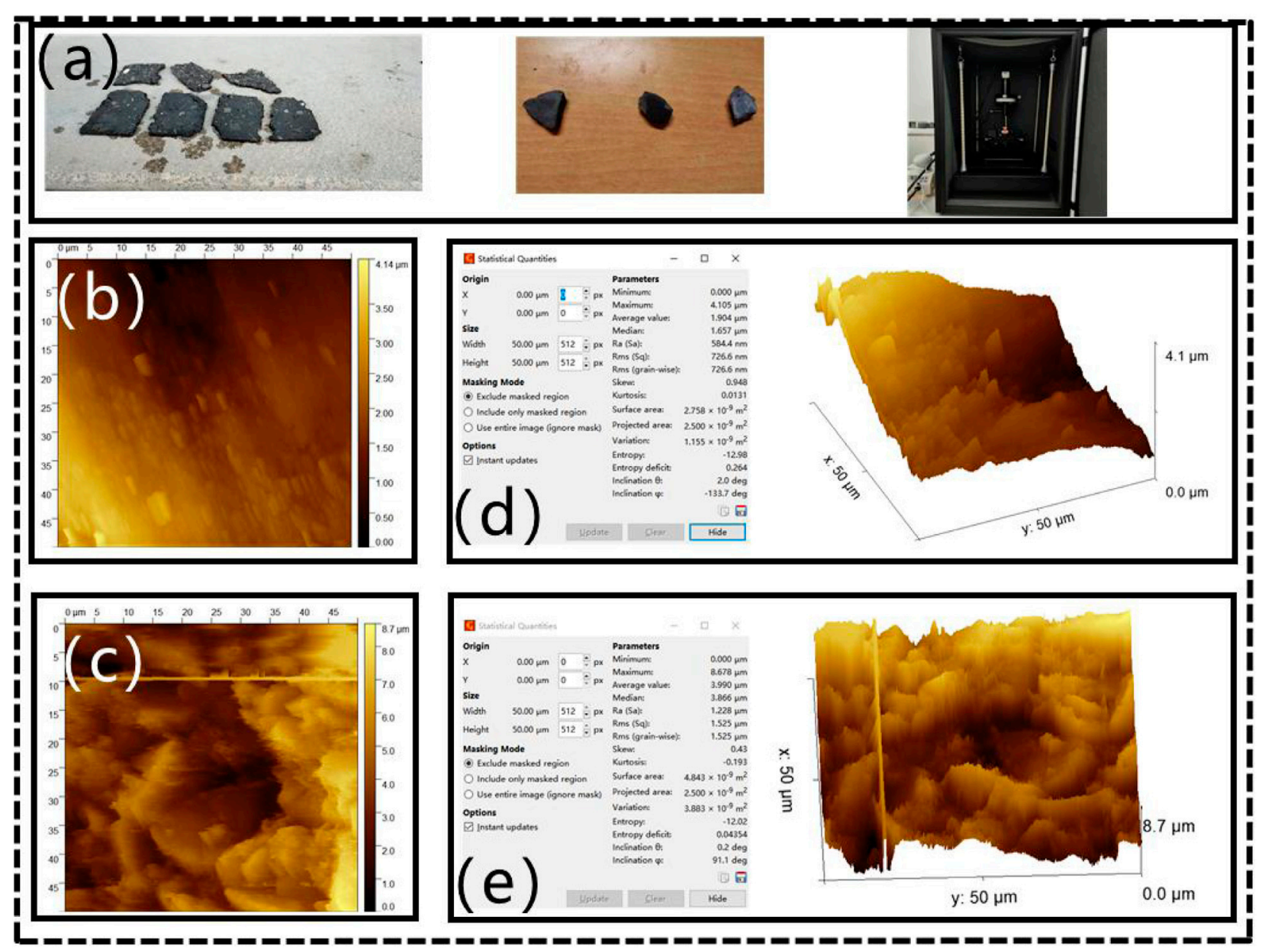

FIGURE 4 | Microscopic tests: (A) test preparation; (B) specimen after 60 days of water immersion; (C) specimen after 120 days of water immersion; (D) scanning area and surface area of steel slag aggregates before water immersion; and (E) scanning area and surface area of steel slag aggregates after immersion.

were tested to evaluate their water damage resistance and tensile deformation resistance. Figure 5 illustrates the low-temperature bending test, the fatigue test, and the water stability test, and the results are presented in Table 5 .

Table 5 indicates that when the SSAM specimen was immersed in water for 120 days, the residual stability, the freeze-thaw splitting strength ratio (TSR), and maximum bending tensile strain at failure met the specification requirements. Furthermore, SSAM had a higher fatigue life, which indicates that the SSAM still has excellent water damage resistance and low-temperature deformation capacity.

However, it should be noted that the expansion of the steel slag aggregate (less than 2\%) and SSAM expansion (less than 1.5\%) met the specification requirements. For a SSAM whose expansion does not meet the requirements, the TSR value and maximum bending tensile strain at failure would be significantly reduced. This is because SSAMs will expand and produce cracks, thus greatly reducing their deformation capacity.

As shown in Figure 6A, the Marshall specimen of the asphalt mixture with unqualified expansion in room temperature water for 120 days had large cracks on its surface, which were mainly caused by the large expansion of the steel slag aggregate. Based on Figure 6B, the stability of the Marshall specimen reached $23.68 \mathrm{kN}$; however, the maximum bending tensile strain of the asphalt mixture with unqualified expansion was only $500 \mu \varepsilon$, and the fatigue life was 3,000 times, which greatly reduced the material's low-temperature tensile deformation resistance ability. When SSAM with unqualified expansion is used to pave roads, it can easily form cracks.

Therefore, the SSAM with qualified expansion has the growth resistance, excellent water damage resistance, and lowtemperature deformation ability. However, the SSAM with unqualified expansion capacity is affected by moisture in the use process, and its low-temperature deformation performance and fatigue performance will be greatly reduced due to expansion cracks. In the process of production, it is inevitable that steel slag with unqualified expansion rate is used in asphalt pavement. In order to reduce the cracking caused by the expansion of steel slag, modified asphalt and fiber can be used in asphalt mixture (Jiang et al., 2020). 


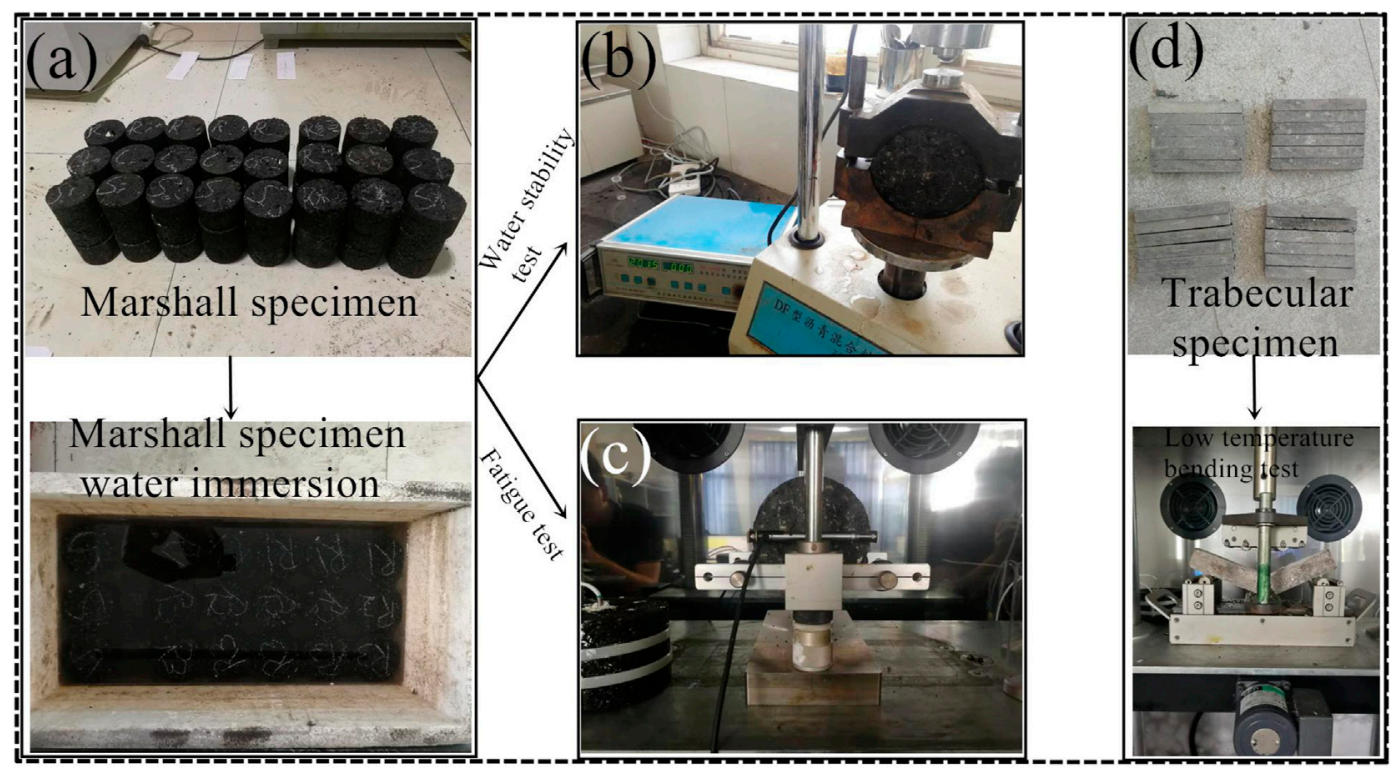

FIGURE 5 | Other road performance tests: (A) Marshall test piece; (B) water stability test; (C) fatigue test; and (D) low-temperature test.

TABLE 5 | Experimental data of water stability and low-temperature deformation performance.

\begin{tabular}{|c|c|c|c|c|}
\hline Type of mixture & Residual stability (\%) & TSR (\%) & $\begin{array}{l}\text { Maximum bending tensile } \\
\text { strain at failure } \\
(\mu \varepsilon)\end{array}$ & Fatigue life (times) \\
\hline SSAM & 90 & 85 & 2,235 & 16,607 \\
\hline LAM & 75 & 68 & 1820 & 13,793 \\
\hline Requirements & $\geqq 80$ & $\geqq 75$ & $\geqq 2000$ & - \\
\hline
\end{tabular}

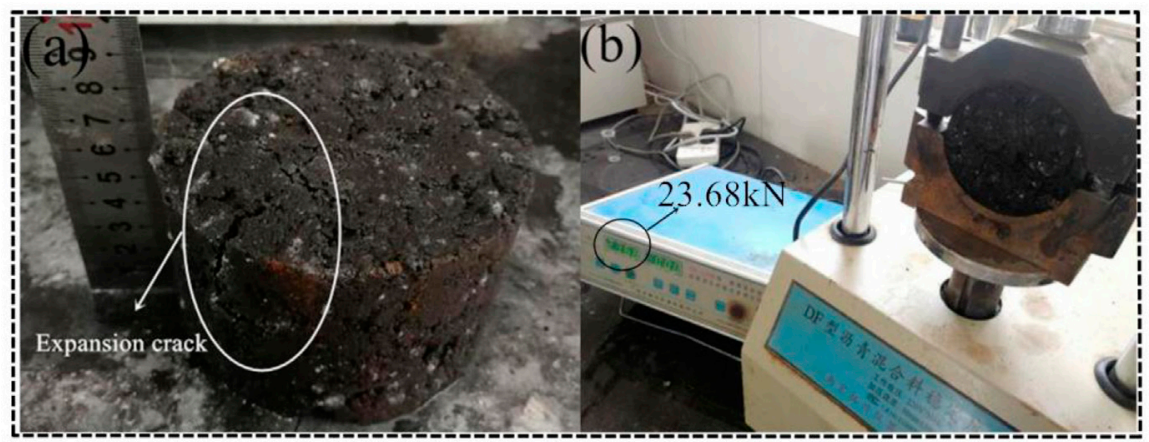

FIGURE 6 | Expansion cracking: (A) Marshall specimen after 120 days of immersion; (B) Marshall stability after 120 days of immersion.

\section{Significance and Engineering Practice of the Research Results}

In China, semirigid base asphalt pavement is the main part of asphalt road. The semirigid base has high stiffness, strong load diffusion capacity, and plays the role of structural bearing, while asphalt pavement only plays the role of functional layer. In order to study the failure mode of semirigid base asphalt pavement structure, ANSYS is used to simulate the structure. The pavement structure, material parameters, and mesh division are shown in Figure 7A, and the profile of pavement structure along the load center is shown in Figure 7B.

From Figures 7C,D, it is clear that the asphalt layer is in a high shear state, and the maximum shear stress appears on the road surface in the wheel gap center, meaning that the pavement 


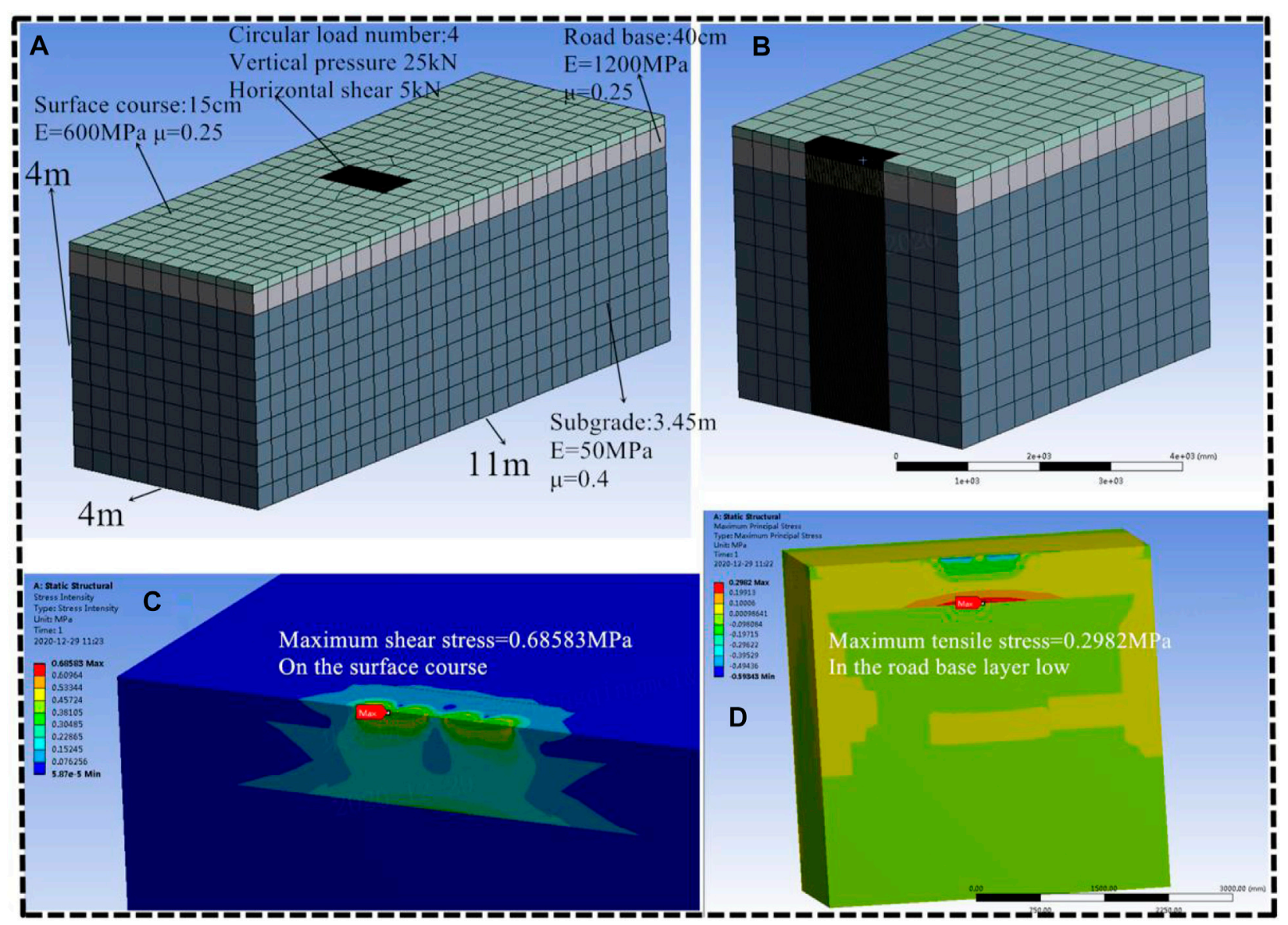

FIGURE 7 | Finite element analysis: (A) mesh dividing; (B) cross section; (C) stress intensity; and (D) maximum principal stress.

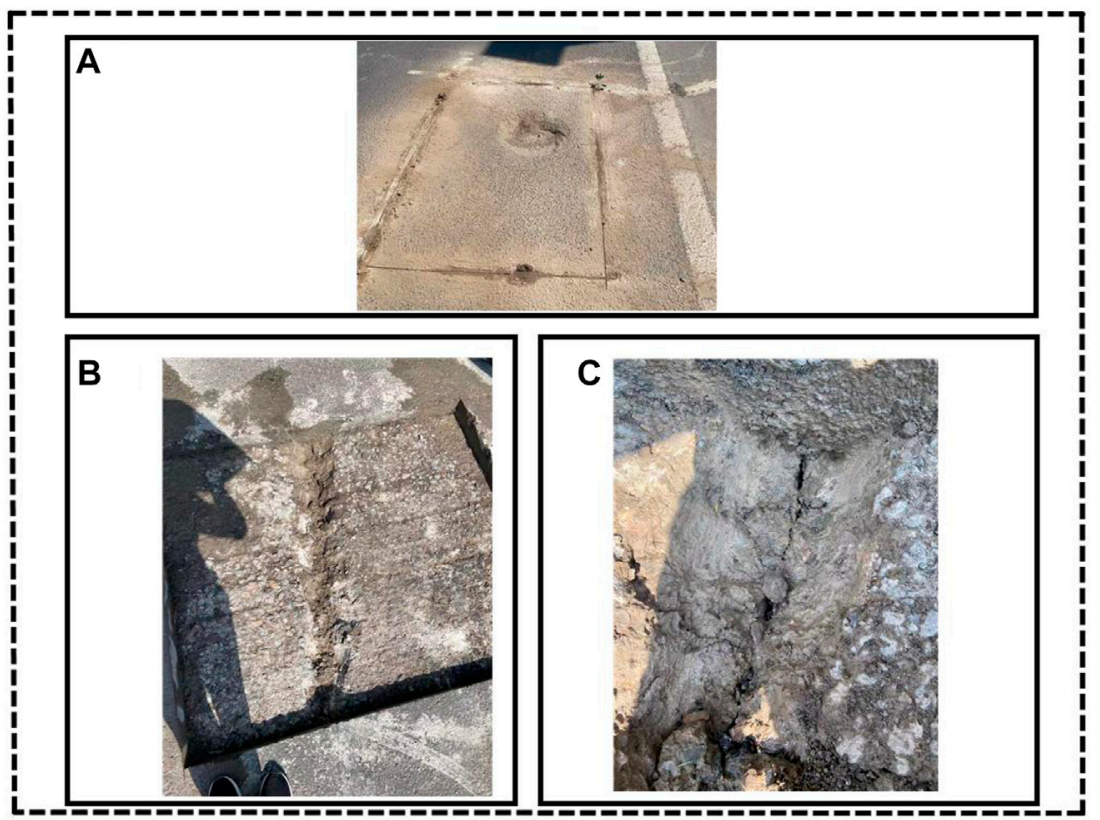

FIGURE 8 | Typical diseases: (A) local settlement of asphalt pavement; (B) removal of asphalt pavement surface; and (C) reflection crack of base course. 


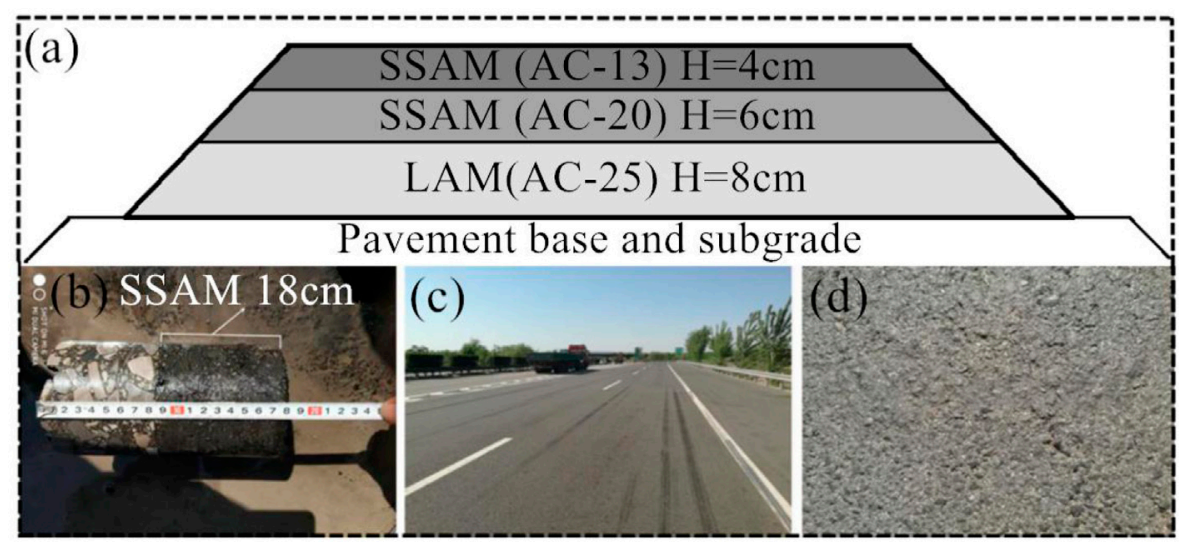

FIGURE 9|Test road: (A) schematic diagram of a main line pavement structure; (B) core drilling sample; (C) condition of the test section; and (D) surface of the test section.

surface can easily undergo permanent deformation. The semirigid base course bears too much bending tensile stress, so the pavement can easily produce reflection cracks (Figure 8). Therefore, most of the pavement issues on China's expressways involve ruts and cracks. In the latest Chinese specifications, the design indices of semirigid pavement include the lowest layer tensile stress of the inorganic binder and the permanent deformation of the asphalt mixture layer.

Under the influence of water, the high-temperature deformation resistance of SSAMs will undergo a certain amount of growth. If the SSAM is paved on the surface of asphalt pavement, it will effectively reduce the permanent deformation of the asphalt pavement to alleviate the development of ruts in semirigid asphalt pavement.

To verify the feasibility of steel slag application in high-grade highways, steel slag with qualified expansion is used in the asphalt pavement surface of a highway in Tangshan city, Hebei Province. The pavement structure is shown in Figure 9A, and core sampling at a representative site location is shown in Figure 9B.

After two years of operation, the surface of the test section was smooth, and there was no cracking, loosening, rutting, or other pavement problems. Therefore, the material demonstrated shows good skid resistance and excellent road performance (Figures 9C,D).

\section{CONCLUSION}

1) After soaking SSAM and LAM in water for 120 days, the dynamic stability of LAM decreased by $73 \%$ relative to that before immersion, and the dynamic stability of SSAM after immersion increased by $50 \%$.

2) Through triaxial compression tests, it was determined that the cohesion of SSAM did not decrease significantly, but that of LAM decreased by $27.1 \%$; the internal friction angle of SSAM increased by $25.1 \%$, and that of LAM decreased by $21.1 \%$. The increase in the internal friction angle and stability of cohesion after immersion led to increased deformation resistance.

3) According to the asphalt adhesion tests, the adhesion between steel slag and asphalt was grade 4 , and that of limestone was grade 2 after boiling for $6 \mathrm{~min}$. The adhesion between steel slag and asphalt was superior to that between limestone and asphalt. Therefore, the reason why the cohesion did not decrease after long-term immersion was that steel slag and asphalt had excellent adhesion.

4) Based on the microscopic test, it was determined that hydration reactions occurred on the aggregate surface of the SSAM after immersion, which produced calcium hydroxide, and other crystals. These crystalline substances increased the surface roughness of the steel slag aggregate and the internal friction angle.

5) The SSAM with qualified expansion demonstrated growth resistance, excellent water damage resistance, and lowtemperature deformation ability. However, the SSAM with unqualified expansion capacity was affected by moisture during use, and its low-temperature deformation performance was greatly reduced because of expansion cracks.

6) Through the ANSYS analysis, it was determined that the semirigid asphalt pavement could easily produce permanent deformations. Additionally, the hightemperature deformation resistance of SSAMs after contact with water could effectively reduce the permanent deformation of asphalt pavement, which alleviated the development of pavement ruts. The steel slag asphalt road that was open to traffic for two years exhibited no cracking, loosening, or rutting, which indicated that SSAMs with qualified expansion can be used in high-grade highways.

\section{DATA AVAILABILITY STATEMENT}

The original contributions presented in the study are included in the article/Supplementary Material, further inquiries can be directed to the corresponding author. 


\section{AUTHOR CONTRIBUTIONS}

$\mathrm{CW}$ executed the experiment, wrote the manuscript, and conceived and designed the study and the experiment plan. $\mathrm{CZ}$ revised the manuscript and analyzed the experimental results.

\section{REFERENCES}

Ameli, A., Hossein Pakshir, A., Babagoli, R., Norouzi, N., Nasr, D., and Davoudinezhad, S. (2020). Experimental Investigation of the Influence of Nano TiO2 on Rheological Properties of Binders and Performance of Stone Matrix Asphalt Mixtures Containing Steel Slag Aggregate. Construction Building Mater. 265, 120750. doi:10.1016/j.conbuildmat.2020.120750

Ameri, M., Hesami, S., and Goli, H. (2013). Laboratory Evaluation of Warm Mix Asphalt Mixtures Containing Electric Arc Furnace (EAF) Steel Slag. Construction Building Mater. 49, 611-617. doi:10.1016/j.conbuildmat.2013.08.034

Barišić, I., Netinger Grubeša, I., and Hackenberger Kutuzović, B. (2017). Multidisciplinary Approach to the Environmental Impact of Steel Slag Reused in Road Construction. Road Mater. Pavement Des. 18, 897-912. doi:10.1080/14680629.2016.1197143

Bonoli, A., Degli Esposti, A., and Magrini, C. (2020). A Case Study of Industrial Symbiosis to Reduce GHG Emissions: Performance Analysis and LCA of Asphalt Concretes Made with RAP Aggregates and Steel Slags. Front. Mater. 7. doi:10.3389/fmats.2020.572955

Chai, C., Cheng, Y., Zhang, Y., Zhu, B., and Liu, H. (2020). Mechanical Properties of Crumb Rubber and Basalt Fiber Composite Modified Porous Asphalt Concrete with Steel Slag as Aggregate. Polymers 12, 2552. doi:10.3390/ polym 12112552

Chen, J.-S., and Wei, S.-H. (2016). Engineering Properties and Performance of Asphalt Mixtures Incorporating Steel Slag. Construction Building Mater. 128, 148-153. doi:10.1016/j.conbuildmat.2016.10.027

Gao, J., Sha, A., Wang, Z., Tong, Z., and Liu, Z. (2017). Utilization of Steel Slag as Aggregate in Asphalt Mixtures for Microwave Deicing. J. Clean. Prod. 152, 429-442. doi:10.1016/j.jclepro.2017.03.113

Gulisano, F., Crucho, J., Gallego, J., and Picado-Santos, L. (2020). Microwave Healing Performance of Asphalt Mixture Containing Electric Arc Furnace (EAF) Slag and Graphene Nanoplatelets (GNPs). Appl. Sci. 10, 1428. doi:10.3390/app10041428

Jiang, Z., Hu, C., Liu, M., Easa, S. M., and Zheng, X. (2020). Characteristics of Morphology and Tensile Strength of Asphalt Mixtures under Impact Loading Using Split Hopkinson Pressure Bar. Construction Building Mater. 260, 120443. doi:10.1016/j.conbuildmat.2020.120443

Jiao, W., Sha, A., Liu, Z., Jiang, W., Hu, L., and Li, X. (2020). Utilization of Steel Slags to Produce thermal Conductive Asphalt Concretes for Snow Melting Pavements. J. Clean. Prod. 261, 121197. doi:10.1016/j.jclepro.2020.121197

Lian, C., Wang, Y., Liu, S., and Hao, Y. (2021). Experimental Study of the Dynamic Compressive and Tensile Strengths of Fly Ash and Slag Based Alkali-Activated Concrete Reinforced with Basalt Fibers. Front. Mater. 8. doi:10.3389/ fmats.2021.651581

Liu, J., Yu, B., and Hong, Q. (2020). Molecular Dynamics Simulation of Distribution and Adhesion of Asphalt Components on Steel Slag. Construction Building Mater. 255, 119332. doi:10.1016/j.conbuildmat.2020.119332

Liu, W., Miao, P., and Wang, S.-Y. (2017). Increasing Microwave Heating Efficiency of Asphalt-Coated Aggregates Mixed with Modified Steel Slag Particles. J. Mater. Civil Eng. 29, 04017171. doi:10.1061/(ASCE)MT.1943-5533.0002026

Lyu, Z., Shen, A., Li, D., Guo, Y., Zhai, C., and Yang, X. (2021). Effect of Dry-Wet and Freeze-Thaw Repeated Cycles on Water Resistance of Steel Slag Asphalt Mixture. Iran J. Sci. Technol. Trans. Civ Eng. 45, 291-301. doi:10.1007/s40996-020-00454-1

Ma, L., Xu, D., Wang, S., and Gu, X. (2020). Expansion Inhibition of Steel Slag in Asphalt Mixture by a Surface Water Isolation Structure. Road Mater. Pavement Des. 21, 2215-2229. doi:10.1080/14680629.2019.1601588

Pathak, S., Choudhary, R., Kumar, A., and Shukla, S. K. (2020). Evaluation of Benefits of Open-Graded Friction Courses with Basic Oxygen Furnace Steel-

\section{FUNDING}

The study was funded by the Natural Science Foundation of Hebei Province (e2012202161); Jiangsu transportation science and technology and achievement transformation project (2018Y25).

Slag Aggregates for Hilly and High-Rainfall Regions in India. J. Mater. Civil Eng. 32, 04020356. doi:10.1061/(ASCE)MT.1943-5533.0003445

Pattanaik, M. L., Choudhary, R., Kumar, B., and Kumar, A. (2021). Mechanical Properties of Open Graded Friction Course Mixtures with Different Contents of Electric Arc Furnace Steel Slag as an Alternative Aggregate from Steel Industries. Road Mater. Pavement Des. 22, 268-292. doi:10.1080/ 14680629.2019.1620120

Preti, F., Noto, S., Accardo, C., Romeo, E., Montepara, A., and Tebaldi, G. (2019). Effect of Hyper-Modified Asphalt Binder and Steel Slags on Cracking and Rutting Behaviour of Wearing Course Mixtures. Road Mater. Pavement Des. 20, S678-S694. doi:10.1080/14680629.2019.1633746

Qazizadeh, M. J., Farhad, H., Kavussi, A., and Sadeghi, A. (2018). Evaluating the Fatigue Behavior of Asphalt Mixtures Containing Electric Arc Furnace and Basic Oxygen Furnace Slags Using Surface Free Energy Estimation. J. Clean. Prod. 188, 355-361. doi:10.1016/j.jclepro.2018.04.035

Tang, Y., Fang, S., Chen, J., Ma, L., Li, L., and Wu, X. (2020). Axial Compression Behavior of recycled-aggregate-concrete-filled GFRP-Steel Composite Tube Columns. Eng. Structures 216, 110676. doi:10.1016/j.engstruct.2020.110676

Tang, Y., Feng, W., Chen, Z., Nong, Y., Yao, M., and Liu, J. (2021a). Experimental and Theoretical Investigation on the Thermo-Mechanical Properties of Recycled Aggregate Concrete Containing Recycled Rubber. Front. Mater. 8. doi:10.3389/fmats.2021.655097

Tang, Y., Feng, W., Feng, W., Chen, J., Bao, D., and Li, L. (2021b). Compressive Properties of Rubber-Modified Recycled Aggregate concrete Subjected to Elevated Temperatures. Construction Building Mater. 268, 121181. doi:10.1016/j.conbuildmat.2020.121181

Wan, J., Wu, S., Xiao, Y., Chen, Z., and Zhang, D. (2018). Study on the Effective Composition of Steel Slag for Asphalt Mixture Induction Heating Purpose. Construction Building Mater. 178, 542-550. doi:10.1016/j.conbuildmat.2018.05.170

Wei, M., Wu, S., Cui, P., Yang, T., and Lv, Y. (2020). Thermal Exchange and Skid Resistance of Chip Seal with Various Aggregate Types and Morphologies. Appl. Sci. 10, 8192. doi:10.3390/app10228192

Zhu, B., Liu, H., Li, W., Wu, C., and Chai, C. (2020). Fracture Behavior of Permeable Asphalt Mixtures with Steel Slag under Low Temperature Based on Acoustic Emission Technique. Sensors 20, 5090. doi:10.3390/s20185090

Ziaee, S. A., and Behnia, K. (2020). Evaluating the Effect of Electric Arc Furnace Steel Slag on Dynamic and Static Mechanical Behavior of Warm Mix Asphalt Mixtures. J. Clean. Prod. 274, 123092. doi:10.1016/j.jclepro.2020.123092

Conflict of Interest: CW was employed by the company Jiangsu JITRI Road Engineering Technology and Equipment Research Institute Co., Ltd.

The remaining authors declare that the research was conducted in the absence of any commercial or financial relationships that could be construed as a potential conflict of interest.

Publisher's Note: All claims expressed in this article are solely those of the authors and do not necessarily represent those of their affiliated organizations, or those of the publisher, the editors and the reviewers. Any product that may be evaluated in this article, or claim that may be made by its manufacturer, is not guaranteed or endorsed by the publisher.

Copyright (C) 2021 Wang and Zhang. This is an open-access article distributed under the terms of the Creative Commons Attribution License (CC BY). The use, distribution or reproduction in other forums is permitted, provided the original author(s) and the copyright owner(s) are credited and that the original publication in this journal is cited, in accordance with accepted academic practice. No use, distribution or reproduction is permitted which does not comply with these terms. 